\title{
Improving Thesis Quality of Graduate Majored in Computer Science
}

\author{
Bo $\mathrm{Li}^{1}$ and Jing $\mathrm{Xie}^{2}$ \\ ${ }^{1}$ College of Computer Science and technology, Wuhan University of Science and Technology, Wuhan, Hubei, China \\ ${ }^{2}$ College of Chemical Engineering and technology, Wuhan University of Science and Technology, Wuhan, Hubei, China \\ liberol@126.com, maryxiejing@gmail.com
}

\begin{abstract}
When accomplishing all the theoretical courses and practice, graduate should offer a thesis to win bachelor degree. However, there are still some problems existed in graduate thesis, which impair the quality. Based on the experience on directing graduate thesis majored in computer science, in this paper, the authors state the status, reason its problems and present some measurements in graduate thesis, which will contribute to improve the thesis quality.
\end{abstract}

Index Terms - Teaching reform, Graduate thesis, Computer science.

\section{Introduction}

Graduate thesis is the most important practical process in graduate training schedule, which is also the final step for graduate to win bachelor degree in China. When carrying out the thesis, theory and practical skills are all required. Moreover, graduate thesis also shows the capability of candidate for bachelor degree to analysis and handle problems with related knowledge that they have learned or should be relearned independently [1-2].

However, due to some reasons [4-9], the quality of graduate thesis is not as good as expected. Candidates for bachelor degree are not well trained and some deficiencies are exposed when handling both theory and practical problems, which make them unqualified for their future studying or jobs. So it is unavoidable to improve the quality of graduate thesis. In this paper, combining to experience to instruct graduate thesis about computer science, the authors describes the status of graduate thesis, reasons its problems and presents some measurements to improve the quality.

\section{Status in Thesis of Graduates Majored in Computer Science}

Thesis is an indispensable practical process for graduates to win bachelor degree, where graduates, supervisors and management departments are all involved and play different roles. Meanwhile, graduate thesis is also a system that integrates theory, professional knowledge and practical skills. Furthermore, if the existing knowledge is not enough to solve the problems occurring to graduate thesis, new knowledge is needed by further studying and then it is put into practice. So learning, practice, exploring and innovation are all contained in graduate thesis. However, in recent years, with the rapid expansion of university, traditional instruction methods can not meet the requirements of graduate thesis, which results in quality reduction. The status in thesis of graduate majored in computer science will be described as follows.

\section{A. Status of graduates}

In china, four-year university studying is divided into 8 semesters and most of universities plan the last two semesters for graduate thesis. During the last two semesters, some activities such as perusing jobs, chasing for master qualification demand graduates to act. In addition, some computer knowledge in classroom fails to meet practical requirements, thus it will be natural thought that graduate thesis is invaluable. To other graduates, graduate thesis seems untouchable tasks.

\section{B. Status of supervisors}

With the rapid expansion of university in China, more and more postgraduates are recruited as teachers. They are successors for doctor or master degree under supervising of their directors. When transforming to supervisors, some deficiencies in experience or skill is displayed to guide graduate thesis. In addition, some supervisors concentrate more on other things instead of graduate thesis, which also shows negative effects on its quality.

\section{Status of management departments}

In some universities, management departments pay more attention on the formation of thesis and care little about what graduates have done, how they complete the tasks and what they have acquired. Following such direction, graduate only focus on formation of thesis and do not try their best to develop software or hardware or present algorithms which graduates majored in computer science aim to approach by conducting thesis.

\section{Reasons Analysis on Graduate Thesis}

Many factors show their effects on thesis quality of graduate thesis. In the following, we will discuss why they have such influence on thesis quality from graduates, supervisors and management departments, respectively.

\section{A. Reasons for graduates}

Quality of graduate thesis has been influenced by many factors including subjective such as job demands and objective as attitude and capability. Some graduates are busy in perusing jobs or chasing for qualification of relearning, they spend much time on other instead of thesis. Some can not positively treat thesis as helpful practice for their future carrier and think 
it senseless, thus they show indifference to thesis. Others have not enough theoretical knowledge, practical skills and relearning capability to accomplish the thesis.

\section{B. Reasons for supervisors}

Presently, many supervisors undertake all kinds of tasks such as teaching, research, industrial development and other social services. They are too busy to instruct the graduates either from energy or from time. Meanwhile, due to various reasons such as low responsibility, some supervisors can not play an active role to guide graduates for their thesis. In addition, some supervisors lack experience of either scientific research or engineering, which result in little supporting to graduates for thesis.

\section{Reasons for management departments}

However, there are so many students majored in varied disciplines that management departments can not set up more specific and comprehensive quality regulations and reasonable approach to assess thesis performance. Thus it will be convenient for them to only concentrate on formation of thesis instead of the final software or hardware or algorithms. Moreover, some regulations on supervisors are not specific, which show low feasibility in justification, implementing and score. Meantime, some management departments still adopt outdated disciplines to manage graduate thesis, which can not step the rapid development on graduate thesis.

\section{Measurements to Improve Thesis Quality of Graduate Majored in Computer Science}

It can be concluded that graduates act primary to thesis because it is completed by them, so the quality are mainly determined by their capability, interests and efforts. Moreover, supervisors' responsibility, capability and concentrations also show significant effects on the thesis quality. During the process of thesis, management departments offer some regulations to be followed by supervisors and graduate and make some inspections to thesis for quality. So in order to improve the quality of graduates majored in computer science, some measurements are presented during each steps in thesis including thesis titles, thesis execution and thesis defence.

\section{A. Thesis titles}

Management departments should inspect graduate thesis titles so strictly that it can avoid some simply repeating as well as remove those nothing to do with computer science.

When offering thesis titles, supervisors should take into account some related factors such as graduates' interests, disciplines and capability. For graduates, some are majored in hardware, some are good at developing software and others are expert in net engineering. So supervisors should give different thesis titles to the corresponding graduates based on their specialty and interests. Moreover, those with capability and creativity should be encouraged to challenge issues with high difficulty. In addition, some graduates want to pursue advanced studies or to find jobs after graduation. Under such circumstances, some theoretical research titles should be appointed to the former, which can establish good foundation for their future research. On the contrary, some practical titles should be allocated to the latter to train their practical skills in advance.

It is also important for graduates to select suitable thesis titles. However, not all titles fit them well. Under such circumstances, graduates should be encouraged to make communication and discuss to their supervisors until ideal titles are presented and accepted by both sides. Meanwhile, graduates are also recommended to present titles themselves. The reason lies in that they will have strong interests on the titles proposed by them and it contributes to accomplish thesis with high quality.

\section{B. Thesis execution}

At first, enough resources including computers and library should be offered to graduates to carry out their thesis. Moreover management departments should formulate some feasible regulations that can be followed by supervisors and graduates. Unexpectedly inspection is also a useful way during thesis execution because management departments can determine to adopt further measurements or not for thesis quality based on the inspection results.

Under the regulations, supervisors should offer thesis plans for each graduate in details. Firstly mission statement should be claimed by supervisors, where clear tasks are defined. Especially for graduates majored in computer science, supervisors should tell graduates what results they should achieved, i.e. software, hardware or algorithms. It is more important that the specific functions about design should be clearly described. Secondly, feasible schedules should be set to ensure the completion of graduate thesis. At same time, responsibility is emphasized again and more time and energy should be spent on thesis by supervisors. For those supervisors short of instruction experience, they should often consult those experts in directing graduates and actively attend some communication seminars about experience and skill on thesis.

Graduates play main role in thesis. So they should know the tasks they have to complete and have ideas on how to achieve them. Moreover, they also know the platform and language will be adopted in thesis. Moreover, regular group meeting is recommended because it can offer more chances for graduates to stay with supervisors, where graduates can report the thesis progress, discuss problems occurring to thesis and obtain some suggestions and supporting from supervisors and then overcome the problems. Meanwhile, it is suggested that graduates should carry out thesis in fixed place, where graduates can discuss each other and focus on thesis.

It must be noted that graduate thesis aims to improve the overall capability of graduate before graduation. That is to say, by graduate thesis, they are capable of re-learning, analysis, reasoning and making solutions because some methods in thesis may not appear in classroom. When encountering these problems beyond their existing knowledge, they can settle them by relearning. Thus, graduates are also encouraged to solve problems by re-learning and re-practice without the help of supervisors, which benefit to improve their capability on research and practice independently. 


\section{Thesis defence}

After thesis is accomplished and all the materials have been prepared, thesis defence should be conducted to justify the performance of graduate thesis.

In thesis defence, management departments should offer more specific feasible regulations to determine the qualification of thesis defence and to offer grades, where those factors are taken into account such as formation of thesis and quality of software, hardware or algorithms. In other words, not only formation of thesis, but also the predefined functions and the efficiency of software, hardware or algorithms must be considered for grades. At the same time, supervisors must be strict with thesis and the corresponding software, hardware or algorithms. Graduates with poor quality on thesis can not be permitted for defence. Moreover, those are also rejected because software, hardware or algorithms designed by them can not implement the predefined functions. It is fair that thesis can be anonymously reviewed. In addition, thesis defence should be serious treated. Firstly, it is welcomed that supervisors are excluded from defence committee. Secondly, grade regulations should be firmly obeyed to reduce some subjective disturbance of defence members. Thirdly, it is justly to make decisions on thesis defence results. Some unqualified thesis defences will fail to award bachelor degree until it satisfies the regulations. But for those with high quality should be praised and be recommended as samples.

\section{Conclusion}

There are many factors that can cause quality reduction in graduate thesis. In this paper, we describe the status and reason the problems on graduate, supervisors and departments of managements which are all involved in quality of thesis. And then, some detailed measurements are presented to solve the problems in graduate thesis about computer science, which aim to improve the quality. Moreover, how to effectively improve the quality of graduate thesis still needs further efforts by graduates, supervisors and management departments.

\section{Acknowledgment}

The authors would like to appreciate the works of anonymous reviewers who make helpful comments to improve the quality of the paper.

\section{References}

[1] Z. Chen, Current Situation and Countermeasures to Graduate Thesis in Engineering Universities, Education in Helongjiang Province, no.12, pp.84-85, 2010

[2] B. Liu and Z. Liu, Reasons and Countermeasures Analysis to Quality Reduction of Graduate thesis in Engineering Universities, Research on College Education, no.7, pp.89-90, 2007

[3] Z. Sun, Measurements on Improving Quality of Graduate Thesis in Engineering Universities, Journal of Zhejiang University of Technology, no.2, pp.200-203, 2005.

[4] Y. Du, Research on Graduate Thesis Education Management. Press of University of Science and Technology of China, pp.12-28, 2007.

[5] Y. Ma, D. Chen, K. Zhang, and Z. Li, How to Improve the Quality of Graduate Design Concerning Computer, Computer Programming Techniques and Maintaining, no.4, pp.110-110, 2011.

[6] L. Luo, Ways of Improving the Quality of Graduate Design in Computer Science, In: Proceedings of Seminar on Computer Application Technology, pp.30-32, 2008.

[7] C. Li, J. He, and F. Huang, Problems and Countermeasures on College Graduate Design in Computer Science, Journal of Neijiang Science and Technology, no.12, pp.185-185, 2012.

[8] Z. Pan, The Methods of Improving the Quality of Computer Major's Graduation Design from the Topic Selection, Journal of Beijing Forestry University, Vol.8, OS1, pp.15-18, 2009.

[9] X. Zhang, Status, problems and countermeasures in graduation design (thesis), China Metallurgical Education, no.4, pp.45-47, 2011. 